\title{
Multidimensional Child Poverty in Ghana: Measurements, Determinants, and Inequalities
}

\author{
Frank Agyire-Tettey, et al. [full author details at the end of the article]
}

Accepted: 5 October 2020 / Published online: 9 October 2020

(C) The Author(s) 2020

\begin{abstract}
Early childhood deprivations and inequalities have social and economic implications in adulthood and thus, their elimination is essential for child development. However, child-level estimates of poverty are rare in low income countries. Using data from two recent rounds of the Ghana Demographic and Health Survey, we measure the extent and sources of childhood deprivations in Ghana and examine subgroup differentials in child poverty. In addition, we examine the child quality-quantity by estimating the causal relationship between number of children and child poverty. Finally, we assess the sources of rural-urban inequalities in child poverty. We find that despite declining incidence and intensity of multidimensional child poverty, significant subgroup differentials persist in Ghana. The findings of the paper reveal that living standards is the main contributor to multidimensional poverty in early childhood in Ghana. Our findings also confirm a significant causal relationship between child quality and quantity in Ghana, there exist a positive relationship between the number of children and the intensity of child poverty in Ghana. Finally, we find that rural-urban inequalities in child multidimensional poverty in Ghana are attributable to differences in observed maternal and household characteristics between rural and urban areas. The persistence of subgroup disparities in child poverty may be detrimental to achieving equitable and inclusive growth in the country. There is the need for considerations of equity, fairness and social justice in the distribution and development of social services and economic infrastructure to ensure even distribution of social and economic opportunities and promote social mobility across groups.
\end{abstract}

Keywords Child poverty $\cdot$ Multidimensional poverty $\cdot$ Inequalities $\cdot$ Deprivations · Decomposition · Ghana

JEL Classification I3 $\cdot \mathrm{I} 30 \cdot \mathrm{I} 32$

Electronic supplementary material The online version of this article (https://doi.org/10.1007/s12187-020$09783-z)$ contains supplementary material, which is available to authorized users. 


\section{Introduction}

Target 1.2 of the Sustainable Development Goals aims to reduce at least by half the proportion of men, women and children of all ages living in poverty in all its dimensions (United Nations, 2015). Children constitute a very vulnerable population globally (Hjelm et al. 2016) and are exposed to multiple deprivations. Early childhood investments in health, nutrition and education are important to cognitive development, income, education and productivity (Currie and Almond 2011; Outes and Porter 2013). As such, early childhood deprivations and experiences of poverty may have lifetime consequences; as well as perpetuating poverty across generations (Corak 2006). Newhouse et al. (2016) estimates that extreme poverty rates for children are twice those for adults globally. Despite the importance of early childhood conditions to the sustainable development agenda, poverty reduction strategies have paid little attention to child poverty especially in developing countries.

Childhood poverty differs from adult poverty (Grantham-McGregor et al. 2007). Children have needs different from adults (Waddington 2004). The vulnerability of children to deprivations and poverty is exacerbated by their high dependency on adults for care, survival, growth and development (Roelen et al. 2010). Thus, child poverty is also implicitly associated with inequality of opportunity and a manifestation of the intergenerational transmission of poverty within households (Bastos and Machado 2009). For equitable and inclusive development, it is important to understand the causes, nature and extent of child poverty and deprivations within country-specific frameworks.

Child poverty is a multidimensional concept (Minujin and Delamonica 2012; Minujin et al. 2012; Qi and Wu 2015). Traditionally, childhood poverty has been measured based on thresholds of unidimensional indicators such as household income or consumption. In such instances, poor children referred simply to children living in households that do not meet some minimum defined threshold of income or consumption (Cantillon et al. 2017). Qi and Wu (2015) argue that child poverty extends beyond insufficient household monetary resources but also includes material and social deprivations, and the lack to essential services such as safe water, improved sanitation, healthcare, education and information. The measurement of child poverty, based on monetary indicators, therefore, does not fully capture the extent and severity of deprivations in early life (Chzhen and Ferrone 2017). There is therefore the need to focus on the non-monetary aspects of deprivations among children.

For the design of effective policies that target vulnerable and deprived children, it is important to measure child poverty within a framework that accounts for the multidimensionality of child poverty and centered on child-specific indicators of well-being. The focus on non-monetary dimensions of child well-being is particularly essential due to the absence of markets for some of the essential components that affect the development of children, including availability and quality of care, protection from violence and abuse and social inclusion. A child-level measure of poverty enables us to investigate intra-household inequalities in resource allocation among children. This is necessary to identify children at risk of temporal and chronic deprivation. Measuring child poverty over time is therefore important to assess progress made towards improving the conditions of children within an inclusive and sustainable development context as well as examine the impacts of interventions on child wellbeing. 
In addition, debate about the so-called child quantity - quality hypothesis has been central to fertility control and poverty reduction strategies in sub Saharan African countries. The hypothesis suggests a trade-off between the number of children and the quality of the children (Becker and Lewis, 1973). If the hypothesis is binding, then small family sizes are expected to lead to improvements in human capital development of the child. Previous studies (Li et al. 2007; Dang and Rogers 2015) have largely studied the child quantity and quality nexus based on a unidimensional measure of child quality, usually based on school enrolment and attendance. Child quality however involves simultaneous deprivations in multiple indicators and dimensions. A childlevel measure of poverty within a multidimensional framework therefore provides a useful setting to re-examine the hypothesized negative relationship existing between the number of children and child quality in developing countries. In addition, there remains a knowledge gap on the changes in the trade-off between child quantity and quality over time in response to policy reforms.

Ghana over the last three decades has made significant progress towards poverty reduction. Indeed, Ghana achieved the Millennium Development Goal of halving poverty from 1990 levels, as the incidence of household poverty reduced from $51.7 \%$ in 1991 to $24.0 \%$ in 2013 (National Development Planning Commission [NDPC], 2015). The period also saw stable economic performance accompanied by a structural transformation of the economy; with the services sector overtaking agriculture as the largest contributor to gross domestic product. On the political front, the country has experienced robust democratic development with the expansion of civil liberties and freedoms since the return to constitutional governance in 1992. In addition, several social intervention programmes aimed at enhancing access to education and healthcare have been implemented. However, substantial challenges remain. There exist pervasive regional differences in access to infrastructure and social services. In addition, the country lags in several improved living conditions such as sanitation and clean household fuels (NDPC, 2015).

Age cohort measurements and individual level analysis of poverty are rare, as poverty measurements have focused on the household as the unit of analysis. As a result, the situation of children during the period of economic and social development as well as political stability presents a key knowledge gap for policymakers and academics alike. The availability of nationally representative datasets, with comprehensive information on the living conditions of children, coupled with methodological improvements in measuring poverty within a multidimensional framework, provide an opportunity to deepen the understanding of the nature, extent and causes of child poverty. Such knowledge is crucial to the design, implementation and evaluation of policies towards the wellbeing of children in Ghana.

The objective of this paper, therefore, is to provide evidence of the trends, nature, sources and determinants of childhood poverty in Ghana, using data from repeated household surveys. The specific objectives of the paper are four-fold. First, the paper measures the extent, sources and trend of childhood deprivations in Ghana within a multidimensional framework by focusing on child specific poverty dimensions nutrition, health, education and living standards. Second, the paper analyses the degree of subgroup variations in multidimensional childhood poverty by examining differences in the incidence of child poverty by gender, location of the household and region of residence. In the third, we seek to re-examine the child quality-quantity nexus within 
a multidimensional poverty framework in Ghana. The last objective assesses the sources of rural-urban inequalities in child poverty by decomposing variations in deprivations into a part attributable to observed difference in characteristics and a component that measures differences in the returns to characteristics.

The paper contributes to the existing literature on child poverty and deprivation in three significant ways. First, the paper provides a country-specific evidence of child poverty in sub Saharan Africa, a region where the wellbeing of children has been least studied. Existing measurements of the levels of child poverty and deprivation have focused on developed countries particularly from the European Union. Second, by using different rounds of the comparable data, we provide a framework for monitoring changes in the incidence and severity of child poverty in Ghana over the period between 2008 and 2014. This framework indirectly serves to evaluate the consequences of the interventions and policies implemented to improve the welfare of children. Finally, estimating and decomposing the determinants of child poverty enables us to identify factors that contribute to the prevalence and sources of inequalities in child poverty in Ghana. The remaining sections of the paper are organised as follows. Section 2 discusses the methodological and analytical strategies employed for the study. Data sources for the study and variables used are described in section 3 . The results and findings of the measurement of multidimensional child poverty and subgroup decompositions are presented in section 4, whilst the determinants and sources of rural-urban inequalities in multidimensional child poverty analysis are presented in sections 5 . The paper concludes with a summary of key findings and recommendations for policy.

\section{Methodology}

\subsection{Multidimensional Poverty Measurement - The Alkire and Foster Approach}

The last two decades have seen advances in the measurement of poverty as the simultaneous deprivations in multiple outcomes. These advances have led to a number of methodological approaches to estimating an index of multiple deprivations such as Atkinson (2003), Chakravarty and D'Ambrosio (2013), Alkire and Foster (2011a, 2011b), and de Neubourg et al. (2012). Multidimensional child poverty in this study is measured based on the methodology proposed by Alkire and Foster (2011a). The unit of analysis of poverty in this study is the child. The Alkire-Foster (AF) measurement of multidimensional poverty is rooted in the Sen's capabilities approach to poverty and based on a dual cut-off procedure.

The AF approach measures the breadth, depth and severity of multidimensional deprivation, similar to the traditional poverty measurement techniques that are based on income or consumption expenditures. The approach is also applicable to indicators that are binary or ordinal. The methodology involves two steps - identification and aggregation. Identification involves two sequential steps. First, we identify who is deprived on each of the indicators, defined by a deprivation cut-off. In the second step, we identify who is multidimensionally poor by comparing individual deprivation scores to a given poverty threshold. Aggregation, on the other hand, defines the overall level of poverty for the sample by summarizing the deprivation and poverty profiles of 
different members. The step employs the aggregation technique of unidimensional poverty measures such as the Foster-Greer-Thorbecke (FGT) methodology adjusted for multidimensionality. Aggregation focuses on only those individuals identified as poor.

The Multidimensional Poverty Index (MPI) created using the AF methodology is a product of two aspects of poverty. First is the incidence of poverty or poverty headcount, which measures the percentage of people who are multidimensionally poor, and second, the intensity of poverty or severity of poverty, which indicates the average percentage of dimensions in which poor individuals are deprived. The dimensions consist of various indicators, and for each dimension and indicator deprivation cut-off is defined. A child is deemed to be deprived in a dimension if he/she falls above the cutoff. A poverty profile is generated in a deprivation matrix and aggregated to obtain the MPI. In this study, three dimensions of child wellbeing are considered - education, health and living conditions. Each dimension is assigned a weight indicating its importance to child poverty in Ghana. In this study, the dimensions are equally weighted, with corresponding indicators also weighted equally as it is difficult to ascertain which dimension or indicator is of greater importance. In addition, Hagerty and Land (2007) have shown that the equal weighting strategy for composite indices of wellbeing is preferable in that it minimizes extreme disagreements among weights for individual indicators.

A child is defined to be multidimensionally poor if the weighted deprivation score of the child on pre-selected indicators exceeds a defined cut-off. We define the deprivation cut-off as one-third (1/3) of the weighted indicators. A poverty cut-off of one-third is normatively justified because it provides a wide distribution of poverty results and captures the acutely poor (Alkire and Santos 2014). The Child-level MPI is obtained by aggregating a deprivation matrix across the population of children. The index of multidimensional child poverty is decomposable by socioeconomic and demographic characteristics such as gender, location of residence, and region of residence. The decomposability property of the index enables us to examine variations in child poverty across socioeconomic groups.

The two aggregate components of Child-MPI are defined as:

$$
\text { Headcount }(\mathrm{H}) \cdot H=\frac{q}{n}
$$

where, $q$ is the number of multidimensionally poor children and $n$ is the total number of children in the population. The severity of poverty or poverty intensity is computed as:

$$
A=\frac{\sum_{i=1}^{n} C_{i}(k)}{q}
$$

where, $C_{i}(k)$ is a censored deprivation score or the average deprivation score across poor children. The censored deprivation score is obtained as an additive function of the weighted indicators

$$
C_{i}(k)=W_{1} I_{i 1}+W_{2} I_{i 1}+\ldots+W_{d} I_{i d}
$$


such that $I_{i j}=1$ if child $i$ is deprived in indicator $j$ and $I_{i j}=0$ otherwise.

$W_{j}$ is the weight attached to indicator $j$, such that $\sum_{j=1}^{d} W_{j}=1$.

The multidimensional child poverty index is obtained as

$$
M P I=H * A=\frac{\sum_{i=1}^{n} C_{i}(k)}{n}
$$

\subsection{Examining the Child Quality-Quantity Nexus}

We examine the child quality-quantity hypothesis within a multidimensional poverty framework by estimating the effects of number of children on the intensity of child poverty. The number of children in a family is potentially endogenous to the multidimensional poverty status of a child. The endogeneity of number of children in a family (fertility) arises from the trade-off that parents make between the quantity of children and the quality of children (Becker and Lewis, 1973). To account for the potential of endogeneity between fertility and child poverty intensity, we adopt the control function approach and explore exogenous variations in the number of children as instruments to estimate the effect of fertility on intensity of child poverty. The empirical model to be estimated is summarized as follows:

$$
\begin{gathered}
N_{j h}=Z_{j h}^{\prime} \beta_{n}+\sigma_{n} \varepsilon_{j h} \\
C_{i j h}=\tau_{c}+X^{\prime} \delta_{c}+N_{j h}^{\prime} \gamma_{c}+e_{i j h}
\end{gathered}
$$

Eqn. 5 models the endogenous variable $\left(N_{j h}\right)$, the number of children of a woman $j$ in household $h$. The model is assumed to be a linear function of a set of observable timevariant characteristics of the mother that are likely to influence the number of children represented by the vector $Z_{j h}$; including the instruments and $\varepsilon_{j h}$ which capture unobserved characteristics that affect decisions about the number of children. The timeinvariant characteristics included in the first-stage regression are the age at first birth and the ethnicity of the woman. Childbearing and fertility beliefs and practices differ among ethnic groups, which may reflect differences in the cultural value of children. As such, the number of children borne by a woman may be influenced by her ethnic background. Ethnicity may therefore account for the influence of cultural norms and beliefs on fertility behaviours of women. The instrumental variable is a measure of age-cohort leave-out-mean fertility rate ${ }^{1}$ in the primary sampling unit (PSU) in which a woman lives. Wodon et al. (2016) adopts a similar instrumentation strategy based on PSU-level measures. PSU level age-cohort fertility is likely to affect the number of children borne

\footnotetext{
${ }^{1}$ Five-year age-cohorts of women are created; 15-19, 20-24, 25-29, 30-34, 35-39, 40-44 and 45-49. The Leave-Out-Mean primary sampling unit (PSU) is calculated as the average number of children per woman within an age-cohort in the PSU, excluding the woman in question.
} 
by a woman but not the intensity of multidimensional child poverty. The age-cohort PSU-level fertility may capture the fertility behaviours of a woman's peers in the community. If fertility behaviours are socially formed, then a positive relationship is hypothesized between the instrument and the number of children borne by a woman.

The second component of the empirical model (Eq. 6) estimates determinants of intensity of multidimensional poverty status of a child $i$ of mother $j$ in household $h$. The vector of explanatory variables $X$ represents a set of child, mother and household characteristics that affect the intensity of child poverty. $e_{i j h}$ is an unobserved error term. Child-specific characteristics included in the model are sex of the child, year of birth and birth spacing, while mother characteristics included are mother's age, years of completed schooling, receipt of labour market income, religious affiliation, access to media, current marital status and status within the household.

The relationship between maternal characteristics and child wellbeing are important for several reasons. First, women are the primary caregivers of children within the Ghanaian cultural and social context. As such, maternal characteristics such as educational attainment, income and decision making within the household are important to the quality of care that a child receives. Also, the relationship between maternal characteristics and investment in child quality, such as human capital may result in the transfer of poor human capital to children that may perpetuate social and economic inequalities as well as reduce social mobility of such children. Household characteristics, on the other hand, included the number of children under 5 years and women (1549 years) in the household, household size, residence type and administrative region fixed effects. The dependent variable, $C_{i j h}$, is a censored deprivation score of each child computed in Eq. 3.

The identification and estimation of the control function method involve two steps. First, the paper estimates an Ordinary Least Squares (OLS) model of the first-stage equation of the number of children and obtain $\widehat{\beta}_{n}$ and $\widehat{\sigma}_{n}$ and the standard residuals $\widehat{\varepsilon}_{j h}=\frac{\left(N-z_{j h}^{\prime} \widehat{\beta}_{n}\right)}{\widehat{\sigma}_{n}}$, where $\widehat{\sigma}_{n}$ is a household clustered standard error.

The second stage involves estimating an OLS model to assess the effect of number of children on intensity of child poverty. The second-stage equation is rewritten as:

$$
C_{i j h}=\tau_{c}+X^{\prime} \delta_{c}+\widehat{N}_{j h} \gamma_{c}^{*}+\widehat{\varepsilon}_{j h} \alpha_{c}^{*}+e_{i j h}
$$

where $\widehat{N}_{j h}$ and $\widehat{\varepsilon}_{j h}$ are the predicted number of children and error terms from the firststage regression. Eq. 7 estimates consistent parameters of $\delta_{c}, \gamma_{c}^{*}$ and $\alpha_{c}^{*}$.

\subsubsection{Robustness check - Lewbel instrument variable estimation}

The paper's instrumentation strategy may be potentially weak. PSU-level age cohort fertility may reflect changes in observed behaviours that may simultaneously affect the number of children and the intensity of multidimensional child poverty. For example, changes in fertility behaviours that arise from improved female education may affect the degree of child poverty through parental attitudes towards investments in child quality. To overcome this challenge, we implement an alternative estimation strategy proposed by Lewbel (2012) that exploits heteroskedasticity for identification. The 
Lewbel (2012) instrumental variable approach is useful when valid external instruments are unavailable or potentially weak. This method provides a framework to check the robustness of the results of the control function method. However, the Lewbel (2012) instrumentation approach may be inefficient due to its reliance on higher order moments. The approach has been applied in several varied situations (Awaworyi Churchill and Smyth 2017; Belfield and Kelly 2012; Buch et al. 2014; Dang and Rogers 2015; Emran and Shilpi 2012; Mishra and Smyth 2015).

The approach uses the fact that the covariance between the error term and some exogenous variables in the first stage regression (number of children) is not zero. Thus, identification is based on the presence of correlation between the residuals and some exogenous variables in the linear regression of the number of children (heteroskedasticity of the first stage regression). Inference from the second-stage regression is not affected as heteroskedasticity occurs at the first stage. In this case, we can interpret $\gamma_{c}^{*}$ as the causal effect of the number of children on the intensity of multidimensional child poverty. In practice, the Lewbel (2012) identification is constructed following three steps. First, obtain the residual (error term) of the first stage regression. Second, calculate the in-sample deviation from the mean for each exogenous variable. Finally, take the product of the residual and the in-sample deviation to obtain the Lewbel instrument. We implement the Lewbel (2012) instrumentation procedure in STATA 16.1 using the command ivreg2h (see Baum and Schaffer (2019) for further details).

\subsection{Inequalities in Multidimensional Child Poverty}

A common approach to examining disparities in outcomes between groups is the Oaxaca (1973) and Blinder (1973) decomposition technique. The technique identifies two sources of outcome differentials between groups - explained or endowment effect and the unexplained or return effect. The endowment effect captures differences in the outcome of interest that arises from observed differentials in endowments or characteristics of groups. The return effect is attributed to differences in the returns to endowments between groups. Thus, each group receives different returns for the same level of endowments.

Following the Oaxaca (1973) and Blinder (1973) technique, the decomposition of rural-urban differentials involves estimating eq. 7 for rural and urban subsample of children separately. For the urban subsample, let the intensity of child poverty be written as $C_{u}$ and $C_{r}$ represents the rural subsample. The difference in the intensity of child poverty between urban and rural areas is obtained as:

$$
C_{u}-C_{r}
$$

A counterfactual structure of the intensity of child poverty is defined as $C^{*}$ which is depicted in the intensity of child poverty in urban areas if they are assigned the characteristics of children in rural areas. Rural-urban inequality in child poverty intensity is obtained as

$$
C_{u}-C_{r}=\left[C_{u}-C^{*}\right]+\left[C^{*}-C_{r}\right]
$$


The first term on the right-hand side of eq. (9) represents the endowment or covariate effect which accounts for contributions of differences in the observed characteristics to the urban-rural child poverty incidence gap. The second term on the right-hand side of the equation captures contribution of returns to characteristics to urban-rural child multidimensional poverty gap.

\section{Data, Variables and Summary Statistics}

\subsection{Data Source}

The paper uses data from the Ghana Demographic and Health Survey (GDHS), implemented by the Ghana Statistical Service (GSS), the Ghana Health Service (GHS) and the National Public Health Reference Laboratory of the GHS. ICF International provided technical assistance through the DHS Program, a USAID-funded project offering support and technical assistance in the implementation of population and health surveys. The primary objective of the GDHS is to generate reliable information on fertility, family planning, infant and child mortality, maternal and child health, and nutrition. The dataset contains information on various characteristics of respondents and households. To date, six rounds of the GDHS have been collected in 1988, 1993, 1998, 2003, 2008 and 2014. Each round of data collection uses similar procedures.

The surveys follow a two-stage sample design. The first stage involves selecting sample points or clusters, consisting of enumeration areas (EAs). The second stage involves a systematic listing of households. A predetermined number of households are randomly selected from each cluster to constitute the total sample size of households. All women aged 15-49 years who are either permanent residents of the household or visitors who stayed in the household the night before the survey are interviewed. A key objective of this is to examine the evolution of sources, determinants and rural-urban inequalities in multidimensional child poverty in Ghana considering the social and economic transformations between 2008 and 2014. As such, the empirical estimations of this paper employs data from the three recent rounds of the GDHS. The 2008 round of the survey interviewed 11,778 households and 5691 women respectively, whilst the 2014 round of the survey interviewed 11,835 households and 9396 eligible women.

\subsection{Dimensions, Indicators, Deprivation Cut-Offs and Weights}

Table 1 presents the dimensions, indicators, deprivation cut-offs and weights employed in the estimation of the child multidimensional poverty index for Ghana. The choice of indicators and deprivations cut-offs has been selected to reflect various aspects of child development based on a basic needs approach. The deprivation cut-offs are selected to be moderate for some indicators and severe for other indicators. Particularly, the indicators of child-level education may be said to be severe. The dimensions are equally weighted; thus, we assign equal importance to each dimension of child deprivation. 
Table 1 Dimensions, indicators, deprivation cut-offs and weights for multidimensional child poverty index

\begin{tabular}{|c|c|c|c|}
\hline Dimensions & Indicators & Deprivation cutoffs & Weights \\
\hline \multirow[t]{6}{*}{ Health } & & & 0.33 \\
\hline & Place of delivery & $\begin{array}{l}\text { A child is deprived if mother delivered out of } \\
\text { an institutional facility }\end{array}$ & 0.07 \\
\hline & Nutrition & $\begin{array}{l}\text { Child is malnourished in terms stunted, wasted } \\
\text { or underweight }\end{array}$ & 0.07 \\
\hline & Immunization & $\begin{array}{l}\text { Child did not receive routine vaccinations } \\
\text { recommended by WHO }\end{array}$ & 0.07 \\
\hline & Child mortality & $\begin{array}{l}\text { A child under five years died in the household } \\
\text { in the five years preceding the survey }\end{array}$ & 0.07 \\
\hline & $\begin{array}{l}\text { Diseases and } \\
\text { sickness }\end{array}$ & $\begin{array}{l}\text { The child suffered cough, diarrhoea, fever or } \\
\text { anemia }\end{array}$ & 0.07 \\
\hline \multirow{5}{*}{$\begin{array}{l}\text { Education, care and social } \\
\text { inclusion }\end{array}$} & & & 0.33 \\
\hline & Care and guidance & $\begin{array}{l}\text { No adult household member ( }+18 \text { years) has } \\
\text { completed } 9 \text { years of schooling }\end{array}$ & 0.08 \\
\hline & School gap & $\begin{array}{l}\text { A child } 11-15 \text { years in the household has not } \\
\text { completed } 5 \text { years of schooling }\end{array}$ & 0.08 \\
\hline & $\begin{array}{l}\text { Early child } \\
\text { development }\end{array}$ & $\begin{array}{l}\text { A child 3-5 years in the household is not } \\
\text { enrolled in early child development program }\end{array}$ & 0.08 \\
\hline & Birth certificate & Child has a birth registration certificate & 0.08 \\
\hline \multirow[t]{5}{*}{ Living standards } & & & 0.33 \\
\hline & Electricity & The household has no electricity & 0.07 \\
\hline & Cooking fuel & $\begin{array}{l}\text { The household cooks with biomass (firewood, } \\
\text { cow dung, wood, charcoal) }\end{array}$ & 0.07 \\
\hline & $\begin{array}{l}\text { Improved } \\
\text { sanitation }\end{array}$ & $\begin{array}{l}\text { The household's sanitation facility is not } \\
\text { improved, or it is shared with other } \\
\text { households }\end{array}$ & 0.07 \\
\hline & Safe water & $\begin{array}{l}\text { The household does not have access to safe } \\
\text { drinking water or safe water is more than a } \\
\text { 30-min }\end{array}$ & \\
\hline \multirow[t]{2}{*}{ round trip } & 0.07 & & \\
\hline & Housing & $\begin{array}{l}\text { Housing materials (wall, roofing and floor) are } \\
\text { rudimentary }\end{array}$ & 0.07 \\
\hline
\end{tabular}

Authors' own computation

The indicators for the health dimension are place of delivery, nutritional status, disease and illness; immunization and child mortality. Birth delivery in an institutional facility with hygienic environment and skilled attendants reduces transmission of infections at birth. A child is defined to be deprived on the place of delivery indicator if the child was delivered in a non-institutional facility. A child is defined to be deprived on nutrition if the child is stunted, wasted or underweight. Stunting is an indicator of long-term malnutrition and measured using height-for-age scores. Wasting on the other hand, is an indicator of current nutritional deficiency and is measured by weight-for-height scores, while underweight captures body mass relative to age and is measured by weight-for-age scores. Weight-for-age captures changes in the magnitude 
of malnutrition over time. A child is identified as malnourished if either their heightfor-age, weight-for-age or weight-for-height score is less than two standard deviations below the median height for the reference category of a specific age and sex. Childhood vaccinations against preventable infections and diseases are deemed essential to improve child survival and development. The indicator captures whether a child had received required basic immunizations. The World Health Organisation and UNICEF recommend that a child receives one dose each of Bacillus Calmette-Guérin (BCG) and measles and three doses each of polio vaccines and Diphteria-Pertussis-Tetanus (DPT) vaccine. A child who has not received the required immunizations for their age is defined as deprived. The disease and sickness indicator capture recent health status of the child. A child is defined as deprived on this indicator if the child suffered an acute respiratory infection, fever, diarrhoea or anaemia in the two weeks preceding the survey. The last indicator of health captures whether the child resides in a household that has recently experienced child mortality. The cut-off defines a child as deprived if a child under five died in the five-year period preceding the survey.

The indicators of the dimension on education, care and social exclusion capture the potential for the household environment to support the adequate growth and development of the child. The quality of childcare is an important indicator of the environment in which a child lives. We measure the quality of care and guidance within the household by the educational attainment of adult household members. A child is deemed to be deprived if he/she resides in a household where no adult member has completed primary schooling; that is nine years of schooling. The environment for educational development of the child is assessed with two indicators. The first indicator, school gap, measures whether all children in the household between 11 and 15 years have completed five years of schooling. The deprivation cut-off identifies households where at least one child in the specified age category has delayed school enrolment or progression. The second indicator captures the potential for early childhood development. Pre-school enrolment has been found to be essential for the development of cognitive and psycho-motor skills of children. A child is classified as deprived if the child resides in a household where at least one child between 3 and 5 years is not enrolled in a pre-school programme. The social exclusion indicator of this dimension captures whether a child has a birth registration certificate.

The physical conditions of the household have significant consequences for health, physical, emotional and cognitive development of children. Equally, these conditions provide an indication of the living standards of children as well as monetary deprivation of households. Five indicators are selected to measure the living standards of children. A child is defined to be deprived if the household does not have access to electricity. The use of biomass as household fuel for cooking have been found to increase respiratory infections among children. We identify a deprived child as residing in a household where biomass is the main source of cooking fuel. Households' access to improved sanitation reduces the risk of drinking water contamination and the spread of diseases. A child is deprived in sanitation if the child lives in a household without an improved sanitation facility or the facility is shared with other households. Access to safe drinking water that is free from disease-causing organisms, toxic chemicals, colour, smell and unpleasant taste is important to prevent the spread of water-borne diseases. In addition, inadequate access to water in the home is also a source of economic disadvantage by requiring a large commitment of human resources to 
fetching and carrying water. A child residing in a household without access to safe drinking water or the source of safe water in a 30-min round-trip from the household is deemed deprived on this indicator. The type of material used for a dwelling's floor, roof and wall may be viewed as an indicator of the quality of housing and health risk. Dwellings made of rudimentary materials such as earth, cow dung and sand may serve as a breeding ground for pests that may pose a health risk to inhabitants. A child living in a house made of low-quality floor, roof or wall materials is deprived in this indicator.

\section{Measurement of Multidimensional Child Poverty in Ghana}

\subsection{Deprivations and Contributions of Indicators}

Table 2 shows the level of deprivation on each indicator of child poverty based on the deprivation cut-off and the contribution of the dimensions and indicators to multidimensional child poverty in 2008 and 2014. The results show that the levels of deprivation on most of the indicators declined between 2008 and 2014. Deprivations on place of delivery declined from $39.6 \%$ in 2008 to $24.7 \%$ in 2014 . The decline may be attributed to the expanded access to maternal healthcare services including delivery under the Free Maternal Healthcare Policy introduced in 2008. The proportion of children deprived on the disease and sickness indicator dropped from $73.9 \%$ in 2008 to $48.3 \%$ in 2014 . Significant reductions in the levels of deprivation on early childhood development are observed between 2008 and 2014; as the proportion of children deprived on the indicator declined from $31.1 \%$ in 2008 to $19.7 \%$ in 2014 . The decline in deprivation during the period may be attributed to the inclusion of early childhood education into the primary school system in Ghana. This led to the expansion of early childhood development facilities in public schools, which previously did not offer preschool programs. Though, deprivations on household cooking fuels and access to improved sanitation declined between 2008 and 2014, deprivations on these indicators continue to remain high despite significant public investments towards enhancing access to clean and safe household cooking fuels and access to improved sanitation and waste disposal. The proportion of children deprived on household cooking fuels dropped from $90.9 \%$ in 2008 to $79.1 \%$ in 2014 whilst deprivation on access to improved sanitation declined to $88.2 \%$ in 2014 from $92.2 \%$ in 2008 .

In terms of the contributions of the dimensions and indicators to the child poverty, the results show that living standards constitute the main source of child deprivations in 2008 and 2014. Living standards accounted for $44.5 \%$ and $43.2 \%$ to child poverty in 2008 and 2014 respectively. The contribution of education, care and inclusion dimension to the multidimensional poverty index increased from $26.8 \%$ in 2008 to $29.4 \%$ whilst the contribution of the health dimension decreased marginally from $28.7 \%$ in 2008 to $27.4 \%$ in 2014. The worsening of deprivation of education, care and inclusion dimension is on the back of increased deprivation in school gap, and care and guidance at the household. The largest contributors to multidimensional child poverty in Ghana are from deprivations on household cooking fuels, access to improved sanitation, and diseases and sickness. In 2008 and 2014, diseases and sickness contributed 10\% to the multidimensional poverty index. Deprivations in household cooking fuels accounted for $12.7 \%$ to multidimensional child poverty in 2008 and increased to $13.1 \%$ in 2014 . 
Table 2 Deprivations and contributions of indicators to child MPI, 2008 and 2014

\begin{tabular}{lccccc}
\hline Indicators & \multicolumn{2}{l}{ Deprived (\%) } & & \multicolumn{2}{l}{ Contributions } \\
\cline { 2 - 3 } \cline { 5 - 6 } & 2008 & 2014 & & 2008 & 2014 \\
\hline Health & & & & $\mathbf{0 . 2 8 7}$ & $\mathbf{0 . 2 7 4}$ \\
Place of delivery & 39.6 & 24.7 & & 0.069 & 0.058 \\
Nutrition & 29.6 & 21.9 & & 0.047 & 0.041 \\
Diseases and sickness & 78.9 & 48.3 & & 0.102 & 0.101 \\
Immunization & 43.1 & 43.1 & & 0.063 & 0.069 \\
Child mortality & 4.1 & 3.3 & & 0.006 & 0.006 \\
Education, care and inclusion & & & & $\mathbf{0 . 2 6 8}$ & $\mathbf{0 . 2 9 4}$ \\
Care and guidance & 40.3 & 35.5 & & 0.086 & 0.096 \\
School gap & 29.3 & 28.7 & & 0.063 & 0.072 \\
Early child development & 31.1 & 19.7 & & 0.065 & 0.053 \\
Birth certificate & 26.7 & 29.2 & & 0.054 & 0.072 \\
Living standards & & & $\mathbf{0 . 4 4 5}$ & $\mathbf{0 . 4 3 2}$ \\
Electricity & 48.6 & 27.0 & 0.084 & 0.063 \\
Cooking fuel & 90.9 & 79.1 & 0.127 & 0.131 \\
Improved sanitation & 92.2 & 88.2 & 0.122 & 0.128 \\
Housing conditions & 41.8 & 30.1 & 0.072 & 0.066 \\
Safe drinking water & 22.8 & 21.6 & 0.040 & 0.044 \\
\hline
\end{tabular}

Source: Authors' own computations

The contribution of deprivation on access to improved sanitation to multidimensional child poverty index was $12.2 \%$ in 2008 to $12.8 \%$ in 2014 .

\subsection{Measurement of Multidimensional Child Poverty in Ghana and Subgroup Decomposition}

Table 3 presents the estimates of the headcount, depth or severity of deprivation and the multidimensional child poverty. The results show declines in the magnitude and severity of child deprivations between 2008 and 2014. The headcount ratio, which measures the proportion of children deprived on one-third $(0.33)$ of the indicators, decreased from $70.8 \%$ in 2008 to $56.8 \%$ in 2014 . On the other hand, the severity or depth of child deprivation decreased at a slower rate between 2008 and 2014. In 2008, multidimensionally poor children were deprived on $52.2 \%$ of the weighted indicators, dropping to $49.6 \%$ in 2014 . The decline in both the poverty headcount and poverty intensity result in a decline in the associated multidimensional poverty index from 0.370 in 2008 to 0.284 in 2014 . Though the results suggest improvements in the livelihood of children between 2008 and 2014, the decline in multidimensional child poverty is the result of a faster drop in the poverty headcount whilst poverty intensity has remained relatively stable over the period. Thus, among multidimensionally poor children, improvements in the intensity of deprivations have been slow, requiring urgent and targeted action towards improving the living conditions of these children. 
Table 3 Measurement of Multidimensional Child Poverty and sub-group decompositions

\begin{tabular}{|c|c|c|c|c|c|c|}
\hline & \multicolumn{3}{|l|}{2008} & \multicolumn{3}{|l|}{2014} \\
\hline & $\mathrm{H}$ & A & MPI & $\mathrm{H}$ & A & MPI \\
\hline National & $\begin{array}{l}0.708 \\
(0.016)\end{array}$ & $\begin{array}{l}0.522 \\
(0.006)\end{array}$ & $\begin{array}{l}0.370 \\
(0.010)\end{array}$ & $\begin{array}{l}0.568 \\
(0.020)\end{array}$ & $\begin{array}{l}0.499 \\
(0.007)\end{array}$ & $\begin{array}{l}0.284 \\
(0.012)\end{array}$ \\
\hline \multicolumn{7}{|l|}{ Sex of child } \\
\hline Male & $\begin{array}{l}0.690 \\
(0.020)\end{array}$ & $\begin{array}{l}0.526 \\
(0.008)\end{array}$ & $\begin{array}{l}0.363 \\
(0.013)\end{array}$ & $\begin{array}{l}0.552 \\
(0.023)\end{array}$ & $\begin{array}{l}0.496 \\
(0.008)\end{array}$ & $\begin{array}{l}0.274 \\
(0.013)\end{array}$ \\
\hline Female & $\begin{array}{l}0.727 \\
(0.020)\end{array}$ & $\begin{array}{l}0.518 \\
(0.007)\end{array}$ & $\begin{array}{l}0.377 \\
(0.012)\end{array}$ & $\begin{array}{l}0.587 \\
(0.025)\end{array}$ & $\begin{array}{l}0.502 \\
(0.008)\end{array}$ & $\begin{array}{l}0.295 \\
(0.014)\end{array}$ \\
\hline \multicolumn{7}{|l|}{ Residence } \\
\hline Urban & $\begin{array}{l}0.463 \\
(0.028)\end{array}$ & $\begin{array}{l}0.438 \\
(0.009)\end{array}$ & $\begin{array}{l}0.203 \\
(0.014)\end{array}$ & $\begin{array}{l}0.347 \\
(0.024)\end{array}$ & $\begin{array}{l}0.437 \\
(0.007)\end{array}$ & $\begin{array}{l}0.152 \\
(0.012)\end{array}$ \\
\hline Rural & $\begin{array}{l}0.873 \\
(0.013)\end{array}$ & $\begin{array}{l}0.553 \\
(0.008)\end{array}$ & $\begin{array}{l}0.483 \\
(0.012)\end{array}$ & $\begin{array}{l}0.759 \\
(0.029)\end{array}$ & $\begin{array}{l}0.523 \\
(0.009)\end{array}$ & $\begin{array}{l}0.397 \\
(0.018)\end{array}$ \\
\hline \multicolumn{7}{|l|}{ Region } \\
\hline Western & $\begin{array}{l}0.663 \\
(0.077)\end{array}$ & $\begin{array}{l}0.529 \\
(0.018)\end{array}$ & $\begin{array}{l}0.351 \\
(0.044)\end{array}$ & $\begin{array}{l}0.561 \\
(0.057)\end{array}$ & $\begin{array}{l}0.469 \\
(0.016)\end{array}$ & $\begin{array}{l}0.263 \\
(0.033)\end{array}$ \\
\hline Central & $\begin{array}{l}0.763 \\
(0.037)\end{array}$ & $\begin{array}{l}0.495 \\
(0.021)\end{array}$ & $\begin{array}{l}0.378 \\
(0.027)\end{array}$ & $\begin{array}{l}0.545 \\
(0.061)\end{array}$ & $\begin{array}{l}0.474 \\
(0.014)\end{array}$ & $\begin{array}{l}0.258 \\
(0.032)\end{array}$ \\
\hline Greater Accra & $\begin{array}{l}0.319 \\
(0.048)\end{array}$ & $\begin{array}{l}0.434 \\
(0.015)\end{array}$ & $\begin{array}{l}0.138 \\
(0.022)\end{array}$ & $\begin{array}{l}0.218 \\
(0.043)\end{array}$ & $\begin{array}{l}0.455 \\
(0.017)\end{array}$ & $\begin{array}{l}0.099 \\
(0.021)\end{array}$ \\
\hline Volta & $\begin{array}{l}0.894 \\
(0.032)\end{array}$ & $\begin{array}{l}0.526 \\
(0.020)\end{array}$ & $\begin{array}{l}0.470 \\
(0.029)\end{array}$ & $\begin{array}{l}0.703 \\
(0.049)\end{array}$ & $\begin{array}{l}0.504 \\
(0.021)\end{array}$ & $\begin{array}{l}0.355 \\
(0.036)\end{array}$ \\
\hline Eastern & $\begin{array}{l}0.699 \\
(0.048)\end{array}$ & $\begin{array}{l}0.476 \\
(0.010)\end{array}$ & $\begin{array}{l}0.333 \\
(0.025)\end{array}$ & $\begin{array}{l}0.596 \\
(0.057)\end{array}$ & $\begin{array}{l}0.503 \\
(0.017)\end{array}$ & $\begin{array}{l}0.300 \\
(0.033)\end{array}$ \\
\hline Ashanti & $\begin{array}{l}0.618 \\
(0.038)\end{array}$ & $\begin{array}{l}0.456 \\
(0.022)\end{array}$ & $\begin{array}{l}0.282 \\
(0.022)\end{array}$ & $\begin{array}{l}0.416 \\
(0.048)\end{array}$ & $\begin{array}{l}0.442 \\
(0.015)\end{array}$ & $\begin{array}{l}0.184 \\
(0.024)\end{array}$ \\
\hline Brong-Ahafo & $\begin{array}{l}0.736 \\
(0.046)\end{array}$ & $\begin{array}{l}0.504 \\
(0.021)\end{array}$ & $\begin{array}{l}0.371 \\
(0.033)\end{array}$ & $\begin{array}{l}0.683 \\
(0.047)\end{array}$ & $\begin{array}{l}0.499 \\
(0.016)\end{array}$ & $\begin{array}{l}0.341 \\
(0.029)\end{array}$ \\
\hline Northern & $\begin{array}{l}0.931 \\
(0.024)\end{array}$ & $\begin{array}{l}0.627 \\
(0.018)\end{array}$ & $\begin{array}{l}0.584 \\
(0.026)\end{array}$ & $\begin{array}{l}0.931 \\
(0.023)\end{array}$ & $\begin{array}{l}0.567 \\
(0.025)\end{array}$ & $\begin{array}{l}0.528 \\
(0.027)\end{array}$ \\
\hline Upper East & $\begin{array}{l}0.900 \\
(0.045)\end{array}$ & $\begin{array}{l}0.580 \\
(0.013)\end{array}$ & $\begin{array}{l}0.522 \\
(0.032)\end{array}$ & $\begin{array}{l}0.862 \\
(0.039)\end{array}$ & $\begin{array}{l}0.520 \\
(0.010)\end{array}$ & $\begin{array}{l}0.448 \\
(0.026)\end{array}$ \\
\hline Upper West & $\begin{array}{l}0.861 \\
(0.036)\end{array}$ & $\begin{array}{l}0.539 \\
(0.019)\end{array}$ & $\begin{array}{l}0.464 \\
(0.028)\end{array}$ & $\begin{array}{l}0.795 \\
(0.040)\end{array}$ & $\begin{array}{l}0.499 \\
(0.024)\end{array}$ & $\begin{array}{l}0.397 \\
(0.035)\end{array}$ \\
\hline
\end{tabular}

Source: Authors' own computations

We proceed to assess sub-group differences in multidimensional child poverty by decomposing the index by some socioeconomic characteristics - sex of the child, residence type of household (rural or urban) and region of household location. By sex of the child, the results show that the poverty headcount is marginally higher among females $(72.7 \%$ in 2008 and $57.8 \%$ in 2014) compared to males $(69.0 \%$ in 2008 and $55.2 \%$ in 2014). On the depth or intensity of poverty however, we do not find significant differences in the degree of deprivations between males and females. The multidimensional poverty index 
was slightly higher for males in 2008 whilst in 2014, the reverse was observed. In both years, the multidimensional child poverty was higher among females than males.

The results reveal significant differences in the incidence and intensity of child poverty between rural and urban areas in Ghana. The incidence and intensity of child poverty are significantly higher in rural areas compared to urban areas in both survey years. We find that in urban areas, $46.3 \%$ of children are multidimensionally poor in 2008 and deprived on $43.8 \%$ of the weighted indicators whilst $87.3 \%$ of children in rural areas were identified as multidimensionally poor and deprived on $55.3 \%$ of the weighted indicators in 2008. Thus, the multidimensional poverty index in 2008 is estimated at 0.203 in urban areas and 0.483 in rural areas in 2008. A similar pattern is witnessed for both the incidence and intensity of child poverty in 2014. The incidence of child poverty is estimated at $34.7 \%$ in urban areas and $75.9 \%$ in rural areas, whilst the intensity or severity of poverty is estimated at $43.7 \%$ and $52.3 \%$ in urban and rural areas respectively. The resultant multidimensional poverty index dropped to 0.152 for urban areas and 0.397 in rural areas. The results are consistent with Adjasi and Osei (2007) and Annim et al. (2012) on monetary poverty in Ghana that finds substantially higher levels of poverty in rural areas.

There exist substantial regional variations in the incidence and intensity of child poverty in Ghana. The incidence of child poverty ranges from $31.9 \%$ in the Greater Accra Region to $93.1 \%$ in the Northern Region in 2008. High rates of poverty incidence are also estimated in the Upper East Region (90.0\%), Upper West Region (86.1\%) and Volta Region (89.4\%). The results show that the severity of child poverty is high in the Northern Region (62.7\%), Upper East Region (58.0\%), Upper West Region (53.9\%) and Volta Region (52.6\%). The lowest levels of poverty deprivation are recorded in the Greater Accra Region at $43.4 \%$ and $45.6 \%$ in the Ashanti Region. The regional-level estimates show high indices of multidimensional child poverty in the Northern Region (0.584), Upper East (0.522) and Volta (0.470) and Upper West (0.464). The results for 2014 indicate reductions in the incidence of poverty across the regions except for the Northern Region where the incidence of child poverty increased marginally.

On the other hand, the degree of poverty intensity remained stable across most of the region with marginal increases in the Greater Accra and Eastern Region. Further, the results show marginal declines in the intensity of poverty in the Northern, Upper East and Upper West Regions. Despite the marginal drops in poverty intensity and incidence of child poverty, there exist persistent high levels of child poverty in the Northern, Upper East, Upper West and Volta Regions. The presence of such locational differences in the levels and intensity of child multidimensional poverty reflects underlying differences in economic opportunities and access to social infrastructure and services. The persistence of such locational disparities requires that urgent efforts are undertaken towards achieving universal access to basic social service and infrastructure as well as equitable and inclusive economic growth. This requires targeted action and interventions towards improving the livelihoods and living conditions of children in deprived regions. 


\section{Determinants and Inequalities in Multidimensional Child Poverty}

\subsection{Determinants of Intensity Child Poverty in Ghana}

The results of the effect of number of children on intensity of child poverty are presented in Table 4. The first-stage estimation is presented in the Appendix to the paper. The first stage estimation results suggest that the age at first birth, ethnic background and the leave-out-mean PSU age cohort fertility explains $40.8 \%$ and $51.0 \%$ of the variation in the number of children borne by a woman. The results show a positive relationship between our instrument and the number of children. This positive relationship suggests that peer-level fertility behaviours may affect the number of children borne by a woman through the transmission of social and cultural values and norms on acceptable fertility behaviours and number of children. In communities where the social and cultural value of children are high, women are likely to have more children. On the other hand, we find a negative relationship between the age of the woman at first birth and the number of children. This suggests delayed childbirth may lead to limited family sizes.

The residual of the first-stage regression is included as an explanatory variable, to account for potential endogeneity between the number of children (fertility) and the

Table 4 Control function method estimation the effect of number of children on intensity of child poverty

(1)

\begin{tabular}{lll}
\hline VARIABLES & 2008 & 2014 \\
Number of children & $0.0223^{* * *}$ & $0.0246^{* * *}$ \\
& $(0.0038)$ & $(0.0036)$ \\
First-stage residuals & $-0.0136^{* *}$ & $-0.0096^{* *}$ \\
& $(0.0057)$ & $(0.0041)$ \\
Female child & 0.0051 & -0.0016 \\
& $(0.0061)$ & $(0.0055)$ \\
Birth spacing of child & -0.0001 & $-0.0004^{* * *}$ \\
& $(0.0001)$ & $(0.0001)$ \\
Constant & $0.5267^{* * *}$ & $0.5389^{* * *}$ \\
& $(0.0450)$ & $(0.0440)$ \\
Child year of birth & Yes & Yes \\
Other controls & Yes & Yes \\
Region fixed effects & Yes & Yes \\
Observations & 1834 & 2037 \\
R-squared & 0.5413 & 0.5796 \\
\hline
\end{tabular}

+ Other household-level controls include total household size, number of children under 5 years, number of women in their reproductive years (15-49 years) and household residence type. Maternal characteristics included as control variables are age, marital status, wage employment, educational attainment, decisionmaking status, and religious affiliation of mother, as well as mother's access to mass media platforms

Robust standard errors in parentheses clustered at primary sampling unit

$* * * p<0.01, * * p<0.05$, * $p<0.1$ 
intensity of child poverty. We find negative relationships between the residual of the first-stage estimation and the intensity of child poverty in the second-stage estimation. The negative relationship suggests that unobserved factors that lead to larger family sizes measured by the number of children decreases the intensity of child poverty in Ghana.

The main interest of the econometric analysis is to examine the relationship between fertility and the intensity of deprivations of a child under five years within the framework of the child quality and quantity debate. As such, estimate the causal effect of number of children on the intensity of multidimensional child poverty. We include in our regression analysis child, maternal and household characteristics as control variables to account for the possible effect of these characteristics on the intensity of child poverty. Hünermund and Louw (2020) however argues that control variables in a regression estimating the causal effect of a variable on another may not have causal interpretations. As such, we refrained from discussing the relationship between maternal and household characteristics and the intensity of child poverty and focus on the main explanatory variable and child characteristics.

We find evidence to support the trade-off between child quality and quantity in Ghana. The results show a positive relationship between number of children and the intensity of child poverty. Thus, as fertility increases, the intensity of child poverty increases. An additional child of the mother increases the intensity of child poverty by 0.022 and 0.025 in 2008 and 2014 respectively. These results are consistent with findings from previous studies including Angrist et al. (2010), Black et al. (2010), Dang and Rogers (2015) and Bougma et al. (2015) that report such child quantity and quality trade-offs.

The trade-off between child quality and quantity may be endemic in low resource environments where credit constraints may be binding on households. Large family size increases intra household competition for resources among siblings that may lead to detrimental consequences for child survival and development. Dang and Rogers (2015) for example shows that increased fertility reduces parental investments in human capital of children in Vietnam. Bougma et al. (2015) also report similar negative effect of sibship size on school achievement in Burkina Faso. Further, in a study of India, Azam and Saing (2018) find a quality-quantity trade-off for some child outcomes. The presence of such trade-offs between child quantity and quality has important implications for poverty reduction and interventions aimed at population and fertility control.

At the child-level, the results show a significant negative relationship between birth spacing and the intensity of child poverty in 2014. Birth spacing enables parents to plan and prepare for childbirth and child-rearing. In low resource settings, birth spacing reduces sibling rivalry especially when household resources and credit constraints are binding (Alderman et al., 2006). Closed spaced births have been reported to increase the risk of malnutrition among children (Dewey and Cohen 2007; Gribble et al. 2009). In addition, we find significant relationships between maternal and household characteristics and the intensity of child poverty. Overall, our results are consistent with the findings of earlier studies such as Asuman et al. (2018), Amarante et al. (2018), Rabbani et al. (2016), Novignon et al. (2015) Lèpine and Strobl (2013) and Imai et al. (2014) on the relationships between these maternal and household characteristics and child wellbeing. 


\subsubsection{Robustness Checks}

The results of the Lewbel (2012) identification by heteroskedasticity instrument variable regression are presented in Table 5. The results show a positive relationship between the number of children and the intensity of multidimensional child poverty in Ghana, consistent with our main findings. These findings confirm the child quality-quantity trade-off such that a large family size (number of children) increases the intensity of child poverty. The magnitude of the effect of number of children on the intensity of child poverty is smaller from the Lewbel instrument variable estimation compared to the estimates of the control function method. The relationship between the intensity of child multidimensional poverty and the other explanatory variables remain robust.

\subsection{Decomposing Inequalities in Intensity of Multidimensional Child Poverty}

The results of the subgroup decomposition of multidimensional child poverty reveal significant rural and urban differences in the incidence and intensity of child poverty. In this subsection, we examine the sources of the differentials in multidimensional child poverty by decomposing the determinants into components attributable to differences in observable characteristics between rural and urban areas and differences arising from the returns to child, mother and household characteristics. A summary of the sources of inequalities in multidimensional child poverty is presented in Table 6.

Table 5 Lewbel IV estimation of the effect of number of children on intensity of child poverty

(1)

VARIABLES

Number of children

Female child

Birth spacing of child

Constant

Child year of birth

Other controls ${ }^{+}$

Region fixed effects

Child year of birth

Observations

R-squared

\section{8}

$0.0150 * * *$

(0.0046)

0.0056

(0.0060)

$-0.0001$

(0.0001)

$0.4759 * * *$

(0.0451)

Yes

Yes

Yes

Yes

1834

0.5377
(2)

2014

0.0149 ***

(0.0045)

$-0.0015$

(0.0055)

$-0.0003 * * *$

(0.0001)

$0.5302 * * *$

(0.0459)

Yes

Yes

Yes

Yes

2037

0.5780

\footnotetext{
+ Other household-level controls include total household size, number of children under 5 years, number of women in their reproductive years (15-49 years) and household residence type. Maternal characteristics included as control variables are age, marital status, wage employment, educational attainment, decisionmaking status, and religious affiliation of mother, as well as mother's access to mass media platforms
}

Robust standard errors in parentheses clustered at primary sampling unit $* * * \mathrm{p}<0.01, * * \mathrm{p}<0.05, * \mathrm{p}<0.1$ 
In 2008 , the average intensity of child poverty in urban areas was 0.320 compared to an average of 0.529 in rural areas. The rural-urban differences in the average intensity of multidimensional child poverty is 0.210 in favour of children in urban areas. In terms of the source of the rural-urban gap in the intensity of child multidimensional poverty, differences in observed characteristics accounted for $58.4 \%$ of the variation in favour of children in urban areas. Thus, differences in the intensity of multidimensional child poverty in Ghana in 2008 arose because of the differences observed in characteristics between rural and urban areas. Equally, differences in the returns to observed characteristics (unexplained gap) favoured children in urban areas. Thus, for similar characteristics, children in urban areas received higher returns compared to children in rural areas.

The results for 2014 show reductions in the average intensity of child poverty in both rural and urban areas. The average intensity of child poverty in urban areas is estimated at 0.294 compared to 0.481 in rural areas. The estimated difference in the average intensity of multidimensional child poverty between rural and urban areas is 0.187 in favour of urban areas. The main source of urban-rural differences in the intensity of child multidimensional poverty is attributable to differences in observed characteristics. The contribution of these observed differences in characteristics accounted for $66.2 \%$ of the source of rural-urban inequalities in multidimensional child poverty. Indeed, both differences in observed characteristics and returns to characteristics continue to favour children in urban areas.

In terms of the contributions to the sources of inequalities, the detailed decomposition in Appendix A2 shows significant contributions of the number of children, years of completed schooling of mother, number of household members and mother's access to media to the component of the gap arising from differences in observed characteristics. These indicators contribute in favour of children in urban areas. On the hand, mother's age, number of resident women in their reproductive ages, and the current marital status of the mother contribute to the unexplained gap in favour of children in urban areas.

Table 6 Summary of Oaxaca-Blinder decomposition of rural-urban inequalities

\begin{tabular}{lll}
\hline Sources & 2008 & 2014 \\
\hline Urban & $0.3198^{* * *}$ & $0.2937 * * *$ \\
& $(0.0097)$ & $(0.0073)$ \\
Rural & $0.5293^{* * *}$ & $0.4811^{* * *}$ \\
& $(0.0089)$ & $(0.0095)$ \\
Difference & $-0.2096^{* * *}$ & $-0.1873 * * *$ \\
& $(0.0131)$ & $(0.0120)$ \\
Explained & $-0.1225 * * *$ & $-0.1239 * * *$ \\
& $(0.0124)$ & $(0.0113)$ \\
Unexplaied & $-0.0871^{* * *}$ & $-0.0634 * * *$ \\
Observations & $(0.0083)$ & $(0.0068)$ \\
\hline
\end{tabular}

Standard errors in parentheses

$* * * \mathrm{p}<0.01, * * \mathrm{p}<0.05, * \mathrm{p}<0.1$

Detailed results are present in Appendix 2 


\section{Conclusions and Policy Recommendations}

The findings of the paper reveal that living standards is the main contributor to multidimensional poverty in early childhood in Ghana between 2008 and 2014. Particularly, households' lack of access to clean and improved household cooking fuels and improved sanitation facilities are the key sources of early deprivations in Ghana. Over the study period, the results show declines in the incidence and intensity of child poverty in Ghana. There exist significant regional and spatial differences in the multidimensional child poverty in Ghana. The persistence of regional disparities in child poverty may be detrimental to achieving equitable and inclusive growth in the country. In terms of the determinants of child poverty in Ghana, we find evidence to confirm a trade-off between child quantity and quality in Ghana. Finally, we find that rural-urban inequalities in child multidimensional poverty in Ghana are attributable to differences in observed maternal and household characteristics between rural and urban areas.

Based on the findings, we have drawn some policy recommendations. First, despite improvements in the levels of deprivations in the various indicators of poverty between 2008 and 2014, there exist substantial deprivations in access to improved sanitation and safe and clean household cooking fuels. The levels of deprivation on access to improved sanitation, and modern cooking fuels are troubling due to their implications for environmental health and indoor air pollution. Ghana, however, has over the years undertaken efforts through interventions such as subsidised liquefied petroleum gas (LPG) policy and clean cook stove initiatives and investments towards improving sanitation and hygiene. Clearly, previous efforts at improving household sanitation and clean and safe cooking fuels have achieved little results. To achieve Goals 6 and 7 of the SDGs on water and sanitation and affordable and clean energy respectively, there is the urgent need to revise the current national strategies aimed at sanitation and clean energy. The revised strategies should aim to increase public investments as well as creating conducive environments for private sector participation in these sectors. In addition, increased investments in these sectors should be accompanied by public education campaigns aimed at behavioural change that facilitates the adoption of clean and safe cooking fuels and improved sanitation. Particularly, there is the need to ensure affordable and reliable provision of clean and safe household cooking fuel sources to discourage the return to biomass fuel for cooking in households. These interventions should be targeted at vulnerable and underserved populations.

The results also showed significant spatial variations in the incidence and intensity of multidimensional child poverty (residency type and administrative regions). Further, a decomposition of the determinants of multidimensional child poverty show substantial contributions of rural-urban variations in observed characteristics to inequalities in multidimensional child poverty. These findings reflect systemic disparities in the distribution and access to basic social services and infrastructure that have transmitted to uneven spatial distribution of economic opportunities. To achieve and sustain inclusive growth and development, there is the need for considerations of equity, fairness and social justice in the distribution and development of social services and economic infrastructure to ensure even distribution of social and economic opportunities and promote social mobility across groups. Indeed, there have been a number of such interventions in recent years aimed at addressing spatial variations in the distribution and access to crucial social and economic infrastructure, such as through specialized agencies as the Savannah Accelerated Development Authority and recently established 
ecological based development authorities. These development authorities should serve as vehicles for improving local livelihoods in deprived communities through the provision of crucial social services in education, sanitation and health.

As medium to long-term strategies for child poverty reduction, some policy interventions are suggested. There is a need to increase the access, adoption and use of family planning services and contraception through the active promotion of the importance of family planning through birth spacing and birth limiting to household welfare and particularly the wellbeing of children. In addition, promoting female education and their subsequent integration into productive economic activities will be essential to mother's access to financial and other resources that would enable them to invest in the welfare of their children. Equally, providing women with alternative livelihoods through skills training that enhances and diversifies their income sources will be crucial for efforts to reducing the incidence and intensity of child poverty in rural areas.

Acknowledgments We thank the team at UNICEF (Ghana office), The Institute for Interdisciplinary Research and Consultancy Services (University of Development Studies) and Professor Agnes Atia Apusigah, who provided insight and expertise that greatly assisted the research. We would also like to show our gratitude to the 2 anonymous reviewers for their valuable comments. The authors are also grateful to Measure DHS for granting access to the data.

Funding Open access funding provided by Lund University. This research received funding from the Ghana Inclusive Development Research Network supported by United Nations International Children's Emergency Fund, Ghana and the University of Development Studies, Tamale and we are grateful to them.

\section{Compliance with ethical standards}

Conflict of interest The authors declare that they have no competing interests.

Open Access This article is licensed under a Creative Commons Attribution 4.0 International License, which permits use, sharing, adaptation, distribution and reproduction in any medium or format, as long as you give appropriate credit to the original author(s) and the source, provide a link to the Creative Commons licence, and indicate if changes were made. The images or other third party material in this article are included in the article's Creative Commons licence, unless indicated otherwise in a credit line to the material. If material is not included in the article's Creative Commons licence and your intended use is not permitted by statutory regulation or exceeds the permitted use, you will need to obtain permission directly from the copyright holder. To view a copy of this licence, visit http://creativecommons.org/licenses/by/4.0/.

\section{References}

Adjasi, C. K., \& Osei, K. A. (2007). Poverty profile and correlates of poverty in Ghana. International Journal of Social Economics, 34(7), 449-471.

Alderman, H., Hoddinott, J., \& Kinsey, B. (2006). Long term consequences of early childhood malnutrition. Oxford economic papers, 58(3), 450-474.

Alkire, S., \& Foster, J. (2011a). Counting and multidimensional poverty measurement. Journal of Public Economics, 95, 476-487.

Alkire, S., \& Foster, J. (2011b). Understandings and misunderstandings of multidimensional poverty measurement. Journal of Economic Inequality, 9, 289-314.

Alkire, S., \& Santos, M. E. (2014). Measuring acute poverty in the developing world: Robustness and scope of the multidimensional poverty index. World Development, 59, 251-274.

Amarante, V., Figueroa, N., \& Ullman, H. (2018). Inequalities in the reduction of child stunting over time in Latin America: Evidence from the DHS 2000-2010. Oxford Development Studies, 1-17. 
Angrist, J., Lavy, V., \& Schlosser, A. (2010). Multiple experiments for the causal link between the quantity and quality of children. Journal of Labor Economics, 28(4), 773-824.

Annim, S. K., Mariwah, S., \& Sebu, J. (2012). Spatial inequality and household poverty in Ghana. Economic Systems, 36(4), 487-505.

Asuman, D., Ackah, C. G., \& Enemark, U. (2018). Inequalities in child immunization coverage in Ghana: Evidence from a decomposition analysis. Health Economics Review, 8(1), 9.

Atkinson, A. B. (2003). Multidimensional deprivation: Contrasting social welfare and counting approaches. The Journal of Economic Inequality, 1(1), 51-65.

Awaworyi Churchill, S., \& Smyth, R. (2017). Ethnic diversity and poverty. World Development, 95, 285-302.

Azam, M., \& Saing, C. H. (2018). Is there really a trade-off? Family size and investment in child quality in India. The BE Journal of Economic Analysis \& Policy, 18(1).

Bastos, A., \& Machado, C. (2009). Child poverty: A multidimensional measurement. International Journal of Social Economics, 36(3), 237-251.

Baum, C., \& Schaffer, M. (2019). IVREG2H: Stata module to perform instrumental variables estimation using heteroskedasticity-based instruments. https://EconPapers.repec.org/RePEc:boc:bocode:s457555

Becker, G. S., \& Lewis, H. G. (1973). On the Interaction between the Quantity and Quality of Children. Journal of Political Economy, 81(2, Part 2), S279-S288.

Belfield, C. R., \& Kelly, I. R. (2012). The benefits of breast feeding across the early years of childhood. Journal of Human Capital, 6(3), 251-277.

Black, S. E., Devereux, P. J., \& Salvanes, K. G. (2010). Small family, smart family? Family size and the IQ scores of young men. Journal of Human Resources, 45(1), 33-58.

Blinder, A. S. (1973). Wage discrimination: Reduced form and structural estimates. Journal of Human Resources, 436-455.

Bougma, M., LeGrand, T. K., \& Kobiané, J. F. (2015). Fertility decline and child schooling in urban settings of Burkina Faso. Demography, 52(1), 281-313.

Buch, C. M., Kesternich, I., Lipponer, A., \& Schnitzer, M. (2014). Financial constraints and foreign direct investment: Firm-level evidence. Review of World Economics, 150(2), 393-420.

Cantillon, B., Chzhen, Y., Handa, S., \& Nolan, B. (Eds.). (2017). Children of austerity: Impact of the great recession on child poverty in rich countries. Oxford University Press.

Chakravarty, S. R., \& D’Ambrosio, C. (2013). A family of unit consistent multidimensional poverty indices. In Poverty and social exclusion around the Mediterranean Sea (pp. 75-88). Springer, Boston, MA.

Corak, M. (2006). Do poor children become poor adults? Lessons from a cross-country comparison of generational earnings mobility. In Dynamics of inequality and poverty (pp. 143-188). Emerald Group publishing limited.

Currie, J., \& Almond, D. (2011). Human capital development before age five. Handbook of Labor Economics, 4, 1315-1486.

Chzhen, Y., \& Ferrone, L. (2017). Multidimensional child deprivation and poverty measurement: Case study of Bosnia and Herzegovina. Social Indicators Research, 131(3), 999-1014.

Dang, H. A. H., \& Rogers, F. H. (2015). The decision to invest in child quality over quantity: Household size and household investment in education in Vietnam. The World Bank Economic Review, 30(1), 104-142.

Dewey, K. G., \& Cohen, R. J. (2007). Does birth spacing affect maternal or child nutritional status? A systematic literature review. Maternal \& Child Nutrition, 3(3), 151-173.

de Neubourg, C., Chai, J., de Milliano, M., Plavgo, I., \& Wei, Z. (2012). Step-by-step guidelines to the multiple overlapping deprivation analysis (MODA), Innocenti Working Paper 2012-10. Florence: UNICEF Office of Research.

Emran, M. S., \& Shilpi, F. (2012). The extent of the market and stages of agricultural specialization. Canadian Journal of Economics/Revue canadienne d'économique, 45(3), 1125-1153.

Grantham-McGregor, S., Cheung, Y. B., Cueto, S., Glewwe, P., Richter, L., Strupp, B., \& International Child Development Steering Group. (2007). Developmental potential in the first 5 years for children in developing countries. The Lancet, 369(9555), 60-70.

Gribble, J. N., Murray, N. J., \& Menotti, E. P. (2009). Reconsidering childhood undernutrition: Can birth spacing make a difference? An analysis of the 2002-2003 El Salvador National Family Health Survey. Maternal \& Child Nutrition, 5(1), 49-63.

Hagerty, M. R., \& Land, K. C. (2007). Constructing summary indices of quality of life: A model for the effect of heterogeneous importance weights. Sociological Methods \& Research, 35(4), 455-496.

Hjelm, L., Ferrone, L., Handa, S., \& Chzhen, Y. (2016). Comparing approaches to the measurement of multidimensional child poverty (p. 29). Florence: Innocenti working paper.

Hünermund, P., \& Louw, B. (2020). On the nuisance of control variables in regression analysis. arXiv preprint arXiv:2005.10314. 
Imai, K. S., Annim, S. K., Kulkarni, V. S., \& Gaiha, R. (2014). Women's empowerment and prevalence of stunted and underweight children in rural India. World Development, 62, 88-105.

Lépine, A., \& Strobl, E. (2013). The effect of women's bargaining power on child nutrition in rural Senegal. World Development, 45, 17-30.

Lewbel, A. (2012). Using heteroscedasticity to identify and estimate Mismeasured and endogenous Regressor models. Journal of Business \& Economic Statistics, 30(1), 67-80.

Li, H., Zhang, J., \& Zhu, Y. (2007). The quantity-quality tradeoff of children in a developing country: Identification using Chinese twins, IZA discussion paper, no. 3012. Bonn: IZA.

Minujin, A., \& Delamonica, D. (2012). Multidimensional child poverty in Tanzania: Analysis of situation, changes and sensitivity of thresholds. Global Child Poverty and Well-Being, 263.

Minujin, A., Minujin, A., \& Nandy, S. (Eds.). (2012). Global child poverty and well-being: Measurement, concepts, policy and action. Policy Press.

Mishra, V., \& Smyth, R. (2015). Estimating returns to schooling in urban China using conventional and heteroskedasticity-based instruments. Economic modelling, 47, 166-173.

National Development Planning Commission. (2015). Ghana millennium development goals 2015 report. Accra: NDPC.

Newhouse, D., Suarez-Becerra, P. and Evans, M. C. (2016). New estimates of extreme poverty for children, Policy Research Working Paper 7845, World Bank.

Novignon, J., Aboagye, E., Agyemang, O. S., \& Aryeetey, G. (2015). Socioeconomic-related inequalities in child malnutrition: Evidence from the Ghana multiple indicator cluster survey. Health Economics Review, 5(1), 34.

Outes, I., \& Porter, C. (2013). Catching up from early nutritional deficits? Evidence from rural Ethiopia. Economics \& Human Biology, 11(2), 148-163.

Qi, D., \& Wu, Y. (2015). A multidimensional child poverty index in China. Children and Youth Services Review, 57, $159-170$.

Rabbani, A., Khan, A., Yusuf, S., \& Adams, A. (2016). Trends and determinants of inequities in childhood stunting in Bangladesh from 1996/7 to 2014. International Journal for Equity in Health, 15(1), 186.

Roelen, K., Gassmann, F., \& de Neubourg, C. (2010). Child poverty in Vietnam: Providing insights using a country-specific and multidimensional model. Social Indicators Research, 98(1), 129-145.

United Nations. (2015). Transforming our world: the 2030 Agenda for Sustainable Development. Division for Sustainable Development Goals: New York, NY, USA.

Waddington, H. (2004). Linking Economic Policy to Childhood Poverty: a review of the evidence on growth, trade reform and macroeconomic policy (Vol. 7). Childhood poverty research and policy Centre.

Wodon, Q., Nguyen, M. C., \& Tsimpo, C. (2016). Child marriage, education, and agency in Uganda. Feminist Economics, 22(1), 54-79.

Publisher's Note Springer Nature remains neutral with regard to jurisdictional claims in published maps and institutional affiliations.

\section{Affiliations}

\section{Frank Agyire-Tettey ${ }^{1} \cdot$ Derek Asuman $^{2} \cdot$ Charles Godfred Ackah ${ }^{3,4}$ • Antoinette Tsiboe-Darko ${ }^{4}$}

Derek Asuman

derek.asuman@med.lu.se

1 Department of Economics, University of Ghana, Accra, Ghana

2 Health Economics Unit, Lund University, Medicon Village 301:5, Scheelevagen 2, 22381 Lund, SE, Sweden

3 Institute of Statistical, Social and Economic Research, University of Ghana, Accra, Ghana

4 Centre for Social Policy Studies, University of Ghana, Accra, Ghana 